TRABAJOS DE PREHISTORIA

69, N. ${ }^{\circ}$ 2, julio-diciembre 2012, pp. 357-374, ISSN: 0082-5638

doi: $10.3989 /$ tp.2012.12097

\title{
Procedencia de las puntas de jabalina del "Dolmen de la Pastora" (Valencina de la Concepción, Sevilla)
}

\author{
Provenance of the javelins from the "Dolmen de la Pastora" \\ (Valencina de la Concepción, Sevilla, Spain)
}

\author{
Mark A. Hunt Ortiz (*) \\ M. Isabel Martínez Navarrete (**) \\ Víctor Hurtado Pérez $(*)$ \\ Ignacio Montero-Ruiz (**)
}

\begin{abstract}
RESUMEN
Este artículo combina una revisión bibliográfica actualizada y una nueva aproximación arqueométrica a las puntas de jabalina tipo La Pastora. Se incluyen recientes resultados del análisis por FRX e isótopos de plomo de ejemplares de este tipo metálico procedentes del "Dolmen de La Pastora" (Valencina de la Concepción, Sevilla) y del yacimiento de La Pijotilla (Badajoz), incorporando los datos de Outeiro de São Bernardo (Moura, Portugal). Las evidencias relacionadas con la interpretación arqueológica contextual de estos tres yacimientos permiten sugerir una fecha para las jabalinas tipo La Pastora en los siglos de transición entre el III y el II milenio a.C. Se confrontan los datos compositivos e isotópicos de las puntas de jabalina con otros elementos metálicos del ámbito regional y con las mineralizaciones caracterizadas isotópicamente en el suroeste de la Península Ibérica, además de con mineralizaciones y elementos metálicos del Mediterráneo oriental. Ello permite defender la producción 'local' de estas jabalinas en el suroeste peninsular, aunque con variaciones tipológicas regionales y a partir de fuentes minerales diversificadas.
\end{abstract}

\begin{abstract}
In this article, along with an updated bibliographical revision, a new archaeometric approach to La Pastora
\end{abstract}

(*) Grupo de investigación ATLAS, Departamento de Prehistoria y Arqueología, Universidad de Sevilla. C/ María de Padilla s/n. 41004 Sevilla.

Correos e.: mhunt@us.es; vhurtado@us.es

(**) Instituto de Historia, Centro de Ciencias Humanas y Sociales-CSIC. C/ Albasanz 26-28. 28037 Madrid. Correos e.: isabel.martinez@cchs.csic.es; ignacio.montero@cchs.csic.es

Recibido: 29-XI-2011; aceptado: 20-III-2012. javelin tip type is presented. New results of XRF and Lead Isotopes analyses of metal objects of this type from the "Dolmen de la Pastora" (Valencina de la Concepción, Sevilla, Spain) and the site of La Pijotilla (Badajoz, Spain) are included, incorporating data from Outeiro de São Bernardo (Moura, Portugal). The evidence related with the interpretation of the archaeological context of these three sites allow to propose a date for these javelins that would stand in the centuries of transition between the $3 r d$ and 2nd millennium BC. The confrontation of compositional and isotopic data from the javelin tips with other metallic elements of the region and with the isotopically characterized mineralization in the southwest of the Iberian Peninsula, in addition to mineralizations and metals of the eastern Mediterranean, support their 'local' production in the peninsular southwest, although with regional typological variations and from diversified mineral sources.

Palabras clave: Suroeste de la Península Ibérica; Prehistoria Reciente; Jabalinas Tipo La Pastora; FRX; Isótopos de Plomo; Procedencia; Próximo Oriente.

Key words: South-West Iberian Peninsula; Recent Prehistory; La Pastora Javelin Type; XRF; Lead Isotopes; Provenance; Near East.

\section{INTRODUCCIÓN}

En 1860 se recuperaron en el tholos (denominado tradicionalmente "cueva" o "dolmen") de La Pastora (Valencina de la Concepción, Sevilla) "hasta 30" puntas de jabalina (Tubino 1868a: 5253). Aún hoy, este depósito resulta singular en la Prehistoria del Mediterráneo occidental por su contenido y lugar de aparición. El monumento 
funerario tiene un corredor de $43 \mathrm{~m}$, el de mayor longitud de los descubiertos en la Península Ibérica (Mederos 2000: 103), y cámara circular con falsa bóveda de 2,5 m de diámetro (García Sanjuán 2009: 230).

Desde el estudio clásico de Almagro (1962) esas piezas metálicas se han utilizado en los debates sobre las relaciones entre las culturas del Mediterráneo oriental y occidental a fines del III milenio a.C. A la defensa tradicional de su origen oriental a partir de su morfología (p. ej., Martín de la Cruz 1991: 113) se propusieron alternativas basadas en un análisis ampliado de la tipología, dispersión y contexto de los paralelos orientales y en el estudio tecnológico y de la composición metálica de las puntas de jabalinas de La Pastora, defendiéndose su producción local a partir, a lo sumo, de una inspiración oriental (Montero y Teneishvili 1996).

Las reacciones a esta interpretación de producción local se centraron, en parte, en los resultados arqueometalúrgicos. Se puso en cuestión la representatividad de los datos analíticos elementales obtenidos, especialmente de los presentes a nivel minoritario/trazas (Mederos 2000: 103; Escacena 2008: 316), reivindicando los análisis de isótopos de plomo para orientar la asignación de procedencia (Mederos 2000: 107). La referencia más reciente a las puntas de jabalina de La Pastora obvia esos datos (Schuhmacher 2011: 418).

Diversas circunstancias interconectadas han confluido en una nueva aproximación arqueométrica al conjunto metálico de La Pastora. En primer lugar, se conocen nuevos datos, ampliándose su dispersión en el suroeste de la Península Ibérica (Hurtado 1995: 75, fig. 4; Hurtado y García Sanjuán 1996; Cardoso et al. 2002). Por otra parte, se ha incrementado en los últimos años de modo considerable el conocimiento de las sociedades implicadas, su organización y cronología, especialmente en lo referido a la caracterización de los recursos minerales y la producción metalúrgica (Hunt 2003; Nocete 2004; Rodríguez Bayona 2008; Nocete et al. 2010; Nocete et al. 2011; Costa Caramé 2011), lo que permite la investigación sobre bases más contrastables. Además, esto se produce en un contexto de resurgimiento internacional del difusionismo orientalista en aquellas comunidades académicas donde era tradicional (Schuhmacher 2011) o de reimplantación en algunas otras donde había desaparecido como tendencia dominante en la década de 1970 tras el impacto de las dataciones por medio de C14 (Roberts 2009; Roberts et al. 2009 discutido en Murillo-Barroso y Montero-Ruiz 2012).

Ahora se pretende contribuir al debate mediante la caracterización de las puntas de jabalina tipo La Pastora conocidas en la Península Ibérica y la revisión de los datos sobre su contexto de aparición, posible cronología y morfología. Estos datos se complementan con nuevos resultados arqueométricos, considerando la representatividad, posibilidades y limitaciones de los procedimientos analíticos empleados (Fluorescencia de Rayos -FRX - e isótopos de plomo), dada su centralidad en las argumentaciones sobre el origen de los ejemplares.

Esta sistematización de la información peninsular servirá de base para el estudio comparativo con la disponible para el Próximo Oriente. Los aspectos tipológicos se han tratado en detalle (Montero y Teneishvili 1996; Mederos 2000), sin nuevas aportaciones externas para datar los alegados prototipos del Mediterráneo oriental para las piezas de la Península Ibérica. Por ello, la valoración de los contactos se centrará en los datos que aportan los metalotectos caracterizados analíticamente en el Mediterráneo oriental.

En resumen, se aportan nuevos datos al estudio de las relaciones externas de las primeras sociedades metalúrgicas de la Península Ibérica a partir de un armamento que para algunos autores se ha venido considerando la prueba más evidente de la existencia de tales relaciones.

\section{PUNTAS DE JABALINA TIPO LA PASTORA EN LA PENÍNSULA IBÉRICA: CONTEXTO Y MORFOLOGÍA}

Como se ha mencionado, el desarrollo de la investigación sobre las sociedades que ocuparon el suroeste de la Península Ibérica en la Prehistoria reciente $\mathrm{y}$, en especial, sobre sus actividades metalúrgicas ha promovido nuevos trabajos de campo, así como la revisión de anteriores intervenciones y del registro arqueológico asociado. Esto ha permitido caracterizar los contextos de procedencia de las puntas de jabalina estudiadas de modo directo en este trabajo (Fig. 1) y la revisión posterior de las asignaciones a este tipo de proyectil aparecidas en la bibliografía en los últimos años. 


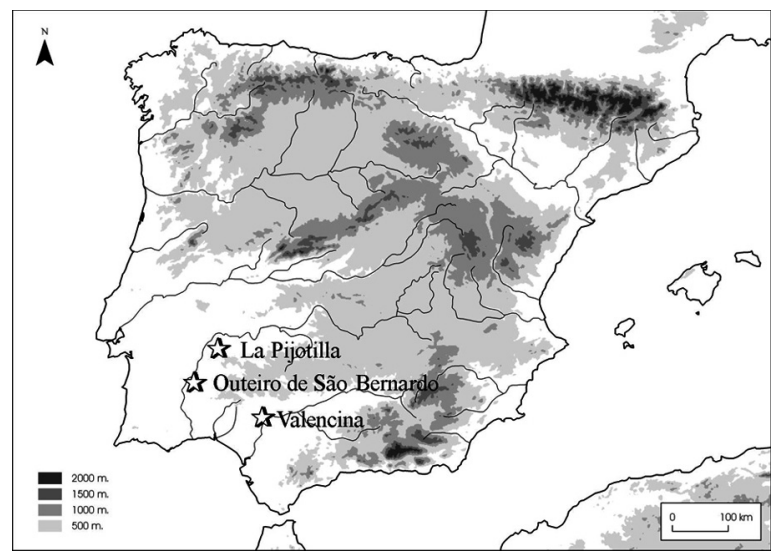

Fig. 1. Localización de los yacimientos del suroeste de la Península Ibérica con puntas de jabalina de tipo $\mathrm{La}$ Pastora.

\subsection{Puntas de jabalina del tholos de La Pastora (Valencina de la Concepción, Sevilla)}

La fecha y pormenores del hallazgo son imprecisos e indirectos; el sepulcro apareció cuando unos obreros cavaban una viña propiedad de Fernando Rodríguez de Rivas, Conde de Castilleja de Guzmán, quien transmite la noticia a Francisco M. ${ }^{\mathrm{a}}$ Tubino (1868b)(1), que los publicó por primera vez. Más de dos décadas después se propondrá "el año 54 ó 55" para el descubrimiento (Candau y Pizarro 1894: 33), que incluía "una especie de urna o caja de barro cocido, de $0,06 \mathrm{~m}$. de espesor" como contenedor de 30 "flechas de metal" (Cañal 1894: 207)(2).

(1) Fernando Rodríguez de Rivas escribe "nada tengo que añadir a lo que exactamente ha referido" Tubino en La Gaceta de 23 de marzo de 1868 (Archivo del Museo Arqueológico Nacional (MAN), Madrid, Donación del Conde de Castilleja de Guzmán, Expte. 1868-17). F. M. Tubino (1868a) y M. Belen (1991: 7) vuelven a publicar ese texto, la segunda "incluyendo los dibujos y planos que no se publicaron entonces" y se custodian en el Archivo del MAN.

(2) Esta y no "las actas de entrega que se conservan en el Museo Arqueológico Nacional de Madrid" son la fuente de la afirmación de M. Almagro Basch (1962: 7) de que las puntas de jabalina aparecieron "en una urna de cerámica". Se han revisado en el Archivo del MAN las actas de donación de F. M. Tubino (Libro Donaciones 4/3/1868, fol. 8v; 1868-1-A-40; MAN-Ingreso jabalinas Pastora Tubino 26/3/1868 Expte. 186852) y las de F. Rodríguez de Rivas (1868-1-A-40; MAN-Ingreso jabalinas Conde Castilleja 2/6/1868, Expte. 1868-17; Libro Donaciones 29/6/1868 fol. 18v).
Tubino (1868b: 1) narra que, a unos $2 \mathrm{~m}$ de profundidad los trabajadores dieron "con una ancha y gruesa piedra" que despertó su curiosidad por su ausencia en la comarca. Al liberar la tierra encontraron otra piedra adyacente. Por indicación del propietario ampliaron el intersticio entre estas losas ("de la cubierta", Mederos 2000: 86) y penetraron en el corredor hasta la cámara. La entrada original, situada al occidente, estaba cegada (Tubino 1868b: 1). Este autor señala dos lugares de procedencia de las puntas metálicas, sin que se cuente con elementos externos a su texto para pensar si, cuando se recogieron, las piezas estaban in situ o desplazadas de su deposición original. Primero se encontraron 2 en "un terreno que cubría una gran piedra"(3) y posteriormente 30 puntas más "no lejos de la entrada artificial del subterráneo", debajo de otra gran piedra, muy cerca de la parte no explorada, debido a un derrumbe, de la galería (Tubino 1868b: 1). Es verosímil que la gran piedra relacionada con el descubrimiento posterior fuera una de las dos losas de cubierta, in situ, por cuya juntura ensanchada se accedió al interior del monumento. El "terreno" que cubría sería el del túmulo de donde procederían las dos primeras puntas. La otra losa, desplazada, se encontraba también "en el exterior del túmulo" (Candau y Pizarro1894: 40), "encima del sitio por donde hoy á él se entra" (Cañal 1894: 207): parece que ambas localizaciones estarían muy próximas.

La mención del contenedor cerámico (con grosor de pared de $6 \mathrm{~cm}$ ) cubierto (intencionalmente o no) por una losa indicaría que se trata de un depósito original, intacto, de 30 piezas (Montero y Teneishvili 1996: 74; García Sanjuán 2005: 91), cuya localización sugiere que "no se encontraban directamente relacionadas con la utilización inicial como espacio funerario del monumento" (Montero y Teneishvili 1996: 74). L. García Sanjuán (2005: 91) interpreta el conjunto metálico como "una deliberada ofrenda (...) sobre su túmulo" conectada con la clausura de la entrada. Su hipótesis relaciona la cronología de las cámaras megalíticas con falsa cúpula del suroeste de la Península Ibérica y la sugerida por la técnica y morfología de las puntas (Montero y

(3) Las actas de entrega de F. M. ${ }^{\text {a }}$ Tubino (véase n. 2) reiteran esta localización: "Dos flechas de bronce, recogidas entre la tierra que cubría una gran piedra inmediata a la [o una] construcción". 
Teneishvili 1996: 80) con la similitud entre la técnica constructiva y materiales de la clausura de la entrada y del corredor (Ruiz Moreno y Martín Espinosa 1993: 555). El sellado simbólico habría tenido lugar "poco tiempo después de la construcción del monumento" (García Sanjuán 2005: 91), concretada entre el 2300-2200 a.C. en relación con una posible orientación del mismo hacia la estrella Sirio (Belmonte y Pimenta 2001: S60; García Sanjuán 2009: 234).

Por otro lado, los recientes resultados de las excavaciones en "La Horca", la zona oriental del poblado prehistórico de Valencina de la Concepción próxima a La Pastora, han mostrado una ocupación desde inicios del III milenio a.C. y otra tardía, clasificada en algún caso como exclusivamente del Bronce Antiguo, de inicios del II milenio a.C. (Cruz-Auñón y Arteaga Matute 2001; Nocete et al. 2008; Vargas et al. 2010; Nocete et al. 2011).

Sobre el número de puntas recuperadas en La Pastora no hay unanimidad. El Conde de Castilleja de Guzmán registra en el expediente de donación al MAN(4), en 1868, "doce flechas que con las dos llevadas ya por (...) Tubino suman la mitad del número de las encontradas". Entregó las otras 14 al Museo Arqueológico de Sevilla (MAS)(5). Como Tubino (1868b: 1) alude a 32, hay que pensar que el donante retuvo 4 puntas, una vez satisfecho de modo equivalente el deber con sus convecinos y con la nación. También lo sugiere que Tubino (1875: 95) afirmara en 1869: le propiétaire (...) me montra quinze flêches en cuivre, trouvées sous una grande pierre non loin de l'entrée de la galerie. Son precisamente 15 las que hay en el MAS (Montero y Teneishvili 1996: 76)(6). El MAN tiene actualmente 13 a resultas de un intercambio con la Cámara de Comptos de Navarra (Pamplona) (Montero y Teneishvili 1996: 76). Las 13 puntas de jabalinas depositadas en el MAN y las 15 que se encuentran en los fondos del MAS conforman el conjunto de las 28 puntas de jabalina de La Pastora que se pudieron estudiar directamente (Montero y Teneishvili 1996), de las que 3, depositadas en el MAN, han sido analizadas mediante isótopos de plomo (Fig. 2).

(4) Véase nota 1.

(5) Candau y Pizarro (1894: 40 y n. 3) reduce el total a 24 y a 12 las guardadas en el MAS.

(6) No hemos encontrado documentación archivística sobre la incorporación al Museo de la decimoquinta punta.

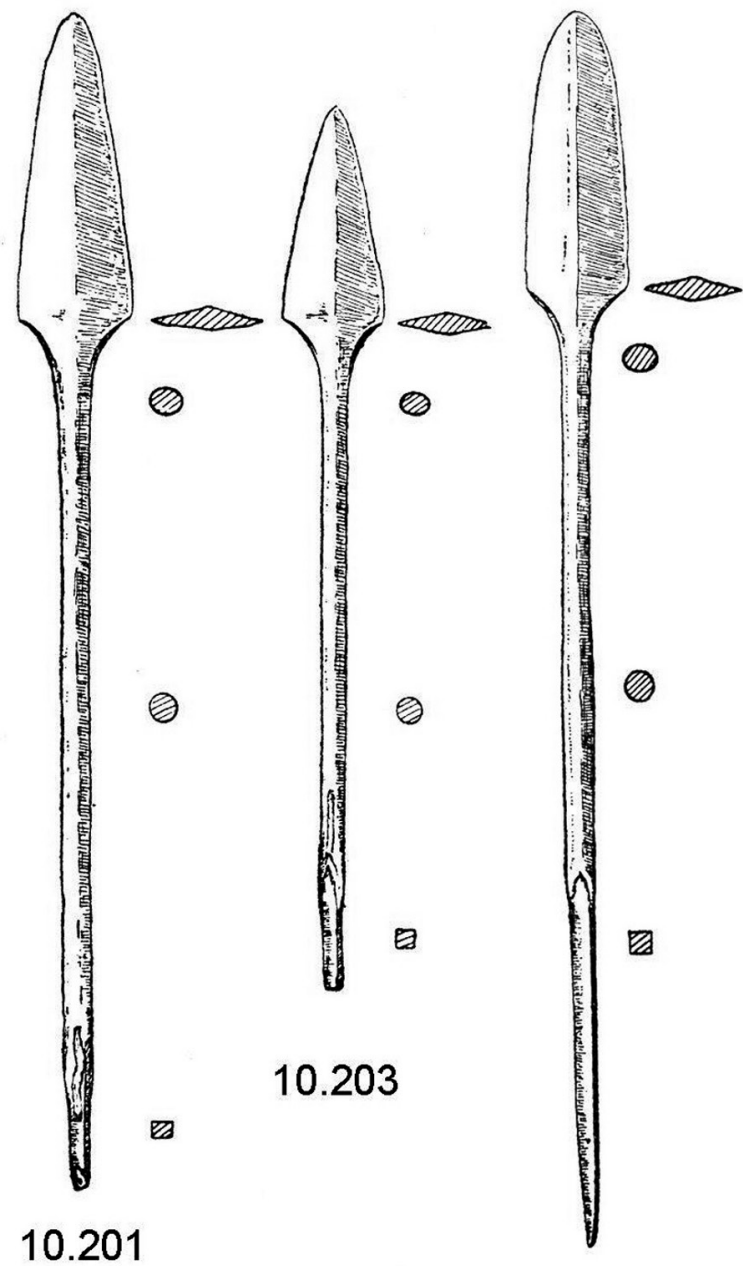

10.197

Fig. 2. Puntas de jabalina del tholos de La Pastora (Valencina de la Concepción, Sevilla) (según Almagro 1962 sin escala; la pieza 10203 aparece sin número en el inventario general y su longitud total es $178 \mathrm{~mm}$ ). Analizadas por isótopos de plomo, depositadas en el Museo Arqueológico Nacional (Madrid).

Morfológicamente (Montero y Teneishvili 1996: 81), las jabalinas de La Pastora se caracterizan por una estructura tripartita: hoja foliácea, pedúnculo y zona de enmangue diferenciada. La hoja es de tendencia triangular con nervadura central, a veces apenas visible (MAS N. ${ }^{\circ} 328-2$ ) y otras combinada con bordes biselados. El pedúnculo es de sección circular, pasando a cuadrada en el enmangue para asegurar la unión con el mango. Las dimensiones, los valores medios en el diámetro del pedúnculo y en el ancho máximo 

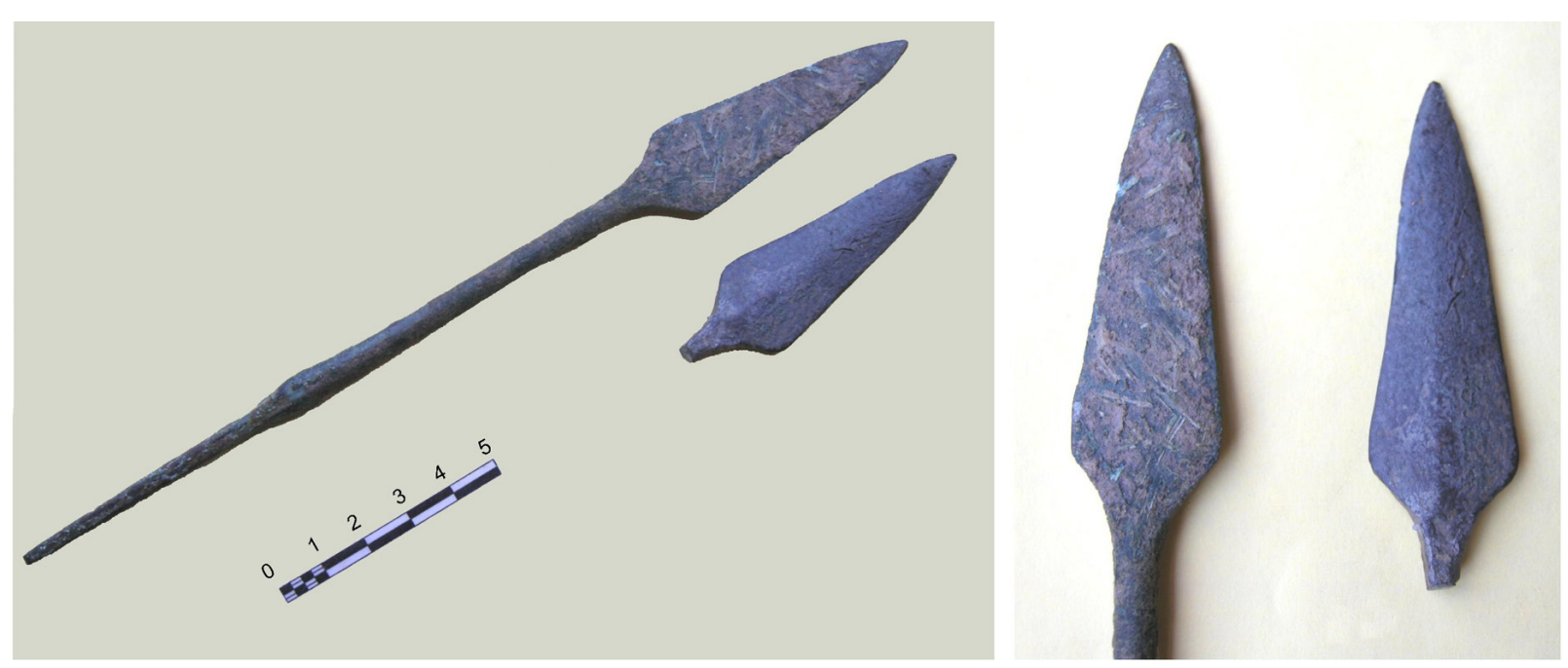

Fig. 3. Puntas de jabalina de La Pijotilla (Badajoz), depositadas en el Museo Arqueológico Provincial de Badajoz: 1. N. ${ }^{\circ}$ inv. 201; 2. N. ${ }^{\circ}$ inv. 219 (fotos M. Hunt).

de la hoja, y lo que es más importante, las relaciones numéricas entre cada uno de los componentes estructurales de las piezas (Montero y Teneishvili 1996: 84, Fig. 5) mostraron el grado de homogeneidad existente en su concepción y fabricación y suministraron los parámetros para su comparación con el restos de modelos con similitudes tipológicas.

\subsection{Puntas de jabalina de La Pijotilla (Badajoz)}

Hurtado Pérez dio a conocer en su tesis doctoral(7) la aparición de puntas de jabalina en el yacimiento de La Pijotilla, tratándose en diversas publicaciones desde entonces (Hurtado Pérez 1988, 1991, 1995; Hurtado Pérez y García Sanjuán 1996; Hurtado Pérez y Hunt Ortiz 1999; Mederos Martín 2000; Cardoso et al. 2002). Las jabalinas, una completa y dos fragmentos, fueron localizadas en superficie por la familia Domínguez. Formaron parte de su colección hasta que el Museo Arqueológico Provincial de Badajoz la adquirió en 2006 (Figs. 3 y 4).

(7) Hurtado Pérez, V. M. 1984: El Yacimiento de La Pijotilla (Badajoz). Estudio de Relaciones Culturales. Tesis Doctoral inédita. Departamento de Prehistoria y Arqueología, Universidad de Sevilla. Véase la p. 428.

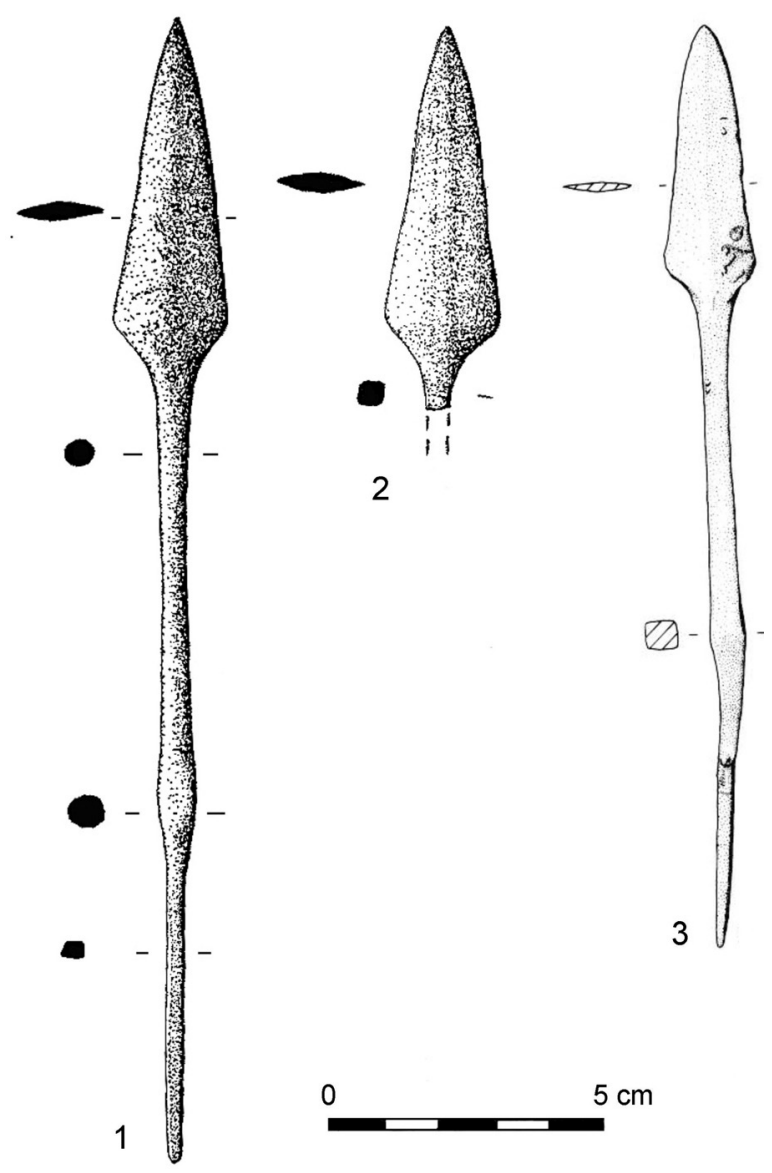

Fig. 4. Puntas de jabalina: 1. N. ${ }^{\circ}$ inv. 201, 2. N. ${ }^{\circ}$ inv. 219 de La Pijotilla (Badajoz) (dibujo V. Hurtado); 3. Outeiro de São Bernardo (Moura, Portugal) (según Cardoso et al. 2002). 
La punta de jabalina completa (N. ${ }^{\circ}$ Inv. 201), de $50 \mathrm{~g}$ de peso, mide $21 \mathrm{~cm}$ de longitud. La hoja tiene $6,5 \mathrm{~cm}$ de longitud y $2,2 \mathrm{~cm}$ de anchura. Presenta una estructura tripartita: hoja, pedúnculo y espiga de enmangue con un engrosamiento entre estas dos últimas partes de secciones circular y cuadrada respectivamente.

De otro ejemplar se conserva la punta foliácea y el inicio de un pedúnculo de sección sub-cuadrangular (N. ${ }^{\circ}$ Inv. 219). Su forma y tamaño es prácticamente igual al anterior, aunque con nervadura más pronunciada. El peso del fragmento es de 20 g. En la Colección Domínguez se guardaba un vástago con pedúnculo y enmangue diferenciados (Hurtado Pérez y Hunt Ortiz 1999: 259-260), quizás la parte que falta en la pieza anterior.

Las excavaciones realizadas en el yacimiento de La Pijotilla, tanto en estructuras domésticas como funerarias, indican una ocupación fundamentalmente durante el Calcolítico. Las dataciones absolutas obtenidas en la secuencia definida en la Estructura 4 abarcan casi todo el III milenio a.C. salvo su último cuarto (Odriozola et al. 2008). Otros indicios permiten pensar en una ocupación tardía, quizás a inicios de la Edad del Bronce. Los contextos, no muy claros y sin dataciones absolutas, se refieren a una fosa en forma ochavada, abierta sobre la tumba circular T2, con campaniforme puntillado geométrico. Una laja de pizarra vertical dividía el interior de la fosa en dos zonas, en una de las cuales se encontraron dos cráneos y un cuenco muy deteriorado. Por otra parte, en el sector sur del yacimiento aparecieron varias tumbas individuales sin ajuar en estructuras a modo de silos o fosas pirifomes. En un principio se podría pensar que correspondieran a la Edad del Bronce por el carácter individual de la inhumación, pero el aumento de hallazgos de este tipo que se está observando en asentamientos calcolíticos no permite asegurar su cronología. Además, en superficie se recogieron objetos que tipológicamente apuntan hacia la Edad del Bronce, como un puñal/alabarda con un remache en la lengüeta y nervadura central (Hurtado Pérez y Hunt Ortiz 1999: 259).

\subsection{Las otras puntas tipo La Pastora del suroeste de la Península Ibérica}

La reciente investigación publicada por M. E. Costa Caramé (2011) incluye este tipo de pieza metálica en su revisión bibliográfica. Se consignan como del tipo La Pastora las puntas de proyectil de la Cueva del Bramadero (Hornachuelos, Córdoba) (Martínez Boloix 1983, 2002) y las portuguesas de Outeiro de São Bernardo (Moura) (Ferreira 1970; Cardoso et al. 2002), Caldeirõa (São Sebastião, Lagos) (Viana et al. 1953; Schubart 1971) y Casal do Pardo, necrópolis de Palmella (Quinta do Anjo) (Berdichewsky Scher 1964). Además, se ha mencionado una posible punta de jabalina (o punta de lanza) procedente de $\mathrm{El} \mathrm{Ca-}$ rambolo (Sevilla) (Carriazo 1973: 307) y otra punta hallada en el poblado amurallado del Cerro dos Castelos de São Brás (Serpa) (Cardoso et al. 2002: $78,93)$. Revisados los datos textuales y gráficos de todas esas referencias, solo parece corresponder al tipo La Pastora la punta de proyectil excavada en Outeiro de São Bernardo (Moura, Portugal) (Fig. 4: 3). Las restantes o son variantes del tipo Palmela o las descripciones no permiten una adscripción clara o, caso de El Carambolo, pueden ser desechadas como puntas de jabalina.

Outeiro de São Bernardo (Moura) es un poblado en altura conocido por los sondeos que Manuel Heleno efectuó en 1946 en su parte superior y por prospecciones superficiales actuales conectadas con la construcción de la presa de Alqueva (Cardoso et al. 2002). Tras una primera y breve descripción de las 16 piezas metálicas halladas por Heleno (Ferreira 1970), se han estudiado de modo completo las conservadas, incorporando los datos de los cuadernos de campo a su caracterización tipológica y analítica: los 13 elementos metálicos identificados en las notas de Heleno apareceram de uma só vez, entre os 20 $\mathrm{cm}$ e os $35 \mathrm{~cm}$ de profundidade, asociados a escasos objectos líticos ou cerámicos (Cardoso et al. 2002: 88). En el sondeo, en el mismo día se recuperaron la punta de jabalina, una pequeña sierra con enmangue de lengüeta y filo cóncavo (a $35 \mathrm{~cm}$ de profundidad) y una gran sierra (a $30 \mathrm{~cm}$ ) (Cardoso et al. 2002: 87). A presença da ponta de jabalina encontrada na parte mais profunda aparentemente atingida pela escavação $(35 \mathrm{~cm})$, exclui, salvo remeximento estratigráfico, idade mais antiga para o restante material metálico (...) o conjunto evidencia uma assinalável tradição calcolítica (Cardoso et al. 2002: 91).

La punta de jabalina tiene espiga larga, de sección sub-cuadrangular, extremo fusiforme para enmangue y $17 \mathrm{~mm}$ de anchura máxima (Cardoso et al. 2002: 85, 93). La longitud, estimada a partir

Trab. Prehist., 69, N. ${ }^{\circ}$ 2, julio-diciembre 2012, pp. 357-374, ISSN: 0082-5638

doi: $10.3989 /$ tp. 2012.12097 
del dibujo original, es de $16,8 \mathrm{~cm}$, sensiblemente inferior a la de los ejemplares completos de La Pastora, que sobrepasan los $23 \mathrm{~cm}$-salvo uno del MAS que mide $21,9 \mathrm{~cm}-$, y al ejemplar completo de La Pijotilla de $21 \mathrm{~cm}$ de longitud.

Según los resultados de un análisis directo sobre la superficie por FRX, sin tratamiento previo, la composición de la punta de jabalina de Outeiro de São Bernardo era de cobre con $>1 \%$ As, sin trazas de $\mathrm{Sn}, \mathrm{Ag}, \mathrm{Sb}, \mathrm{Pb}$ y $\mathrm{Fe}$ (Cardoso et al. 2002: 88-89, Tab. 1).

La tipología de las piezas de Outeiro de São Bernardo y su composición otorgan al conjunto un carácter homogéneo desde el punto de vista cronológico-cultural. Ello unido al hallazgo en el poblado de cerámicas campaniformes del grupo inciso, generalmente asociadas a algunos de los tipos allí identificados, llevó a Cardoso y sus colaboradores (2002: 101) a situar o conjunto metálico no final do Calcolítico/início da Idade do Bronze, correspondente aos últimos séculos do III Milénio a.C. Lo valoran como el conjunto metálico doméstico más importante del occidente de la Península Ibérica correspondiente a una única ocupación campaniforme (Cardoso et al. 2002: 77).

Estos mismos autores (Cardoso et al. 2002: 97) también mencionan una punta de cobre arsenical del Cerro dos Castelos de São Brás (Serpa) con el pedúnculo fragmentado. Según la información publicada (Parreira 1983: 153, 164, Fig. 12, n. ${ }^{\circ} 8$ ), en nuestra opinión se asemeja más a una de tipo Palmela que a la punta de jabalina de Outeiro de São Bernardo, aunque ambas tienen sección cuadrangular.

\section{PUNTAS DE JABALINA TIPO LA PASTORA EN LA PENÍNSULA IBÉRICA: LOS ANÁLISIS ELEMENTALES}

Los resultados de todos los análisis de composición de las puntas de jabalina, desde el pri- mero de Siret (1913: 400) a los que ahora se presentan de las piezas de La Pijotilla mediante FRX (Tab. 1), señalan que la composición es de cobre o cobre arsenicado.

Solamente los datos de los Studien zu den Anfängen der Metallurgie (SAM) publicados por el laboratorio de Stuttgart (Junghans et al. 1968) contradicen los previos de Almagro (1962: 14). La pieza del Museo de Sevilla analizada en la primera serie del SAM (Junghans et al. 1960: n. ${ }^{\circ}$ 830) ofrecía un contenido de estaño significativo $(1,9 \% \mathrm{Sn})$, elemento no detectado en el análisis realizado en el Proyecto de Arqueometalurgia (Rovira Llorens et al. 1997: 345, PA6582). Esta anomalía y otros análisis considerados erróneos (Hunt Ortiz 2003: 311), así como unas limitaciones exclusivas de los elementos trazas, pero ampliadas a los mayoritarios para el estudio de procedencia (Mederos 2000: 103), han llevado a autores posteriores (Escacena 2008: 316) a cuestionar la validez general de los análisis.

Parece entonces oportuno recalcar que los análisis elementales efectuados con distintas técnicas y en épocas diferentes pueden presentar discrepancias cuantitativas. Sin embargo la contradicción entre la presencia/ausencia de ciertos elementos en proporciones significativas o incluso mayoritarias es difícil de explicar y debería ser considerada causa de errores procedimentales o incluso tipográficos. Pero la identificación de un elemento excepcional, como el estaño, en un análisis antiguo de una muestra que, además, no fue analizada de forma inmediata a la extracción no puede servir para anticipar "otros resultados" que no sean cobre o cobre arsenicado. Tales resultados y la ausencia de $\mathrm{Sn}$, esperables antes de analizar las puntas de jabalina de La Pijotilla (Hunt Ortiz 2003: 313), fueron los obtenidos (Tab. 1).

La validez de los elementos traza como argumento para apoyar la manufactura local requiere algunas matizaciones. El margen de error en los

\begin{tabular}{|l|l|c|c|c|c|c|c|c|c|c|}
\hline Análisis & Yacimiento & Invent. & $\mathbf{F e}$ & $\mathbf{N i}$ & $\mathbf{C u}$ & $\mathbf{A s}$ & $\mathbf{A g}$ & $\mathbf{S n}$ & $\mathbf{S b}$ & $\mathbf{P b}$ \\
\hline PA3783 & La Pastora & 10197 & 0,05 & 0,08 & 98,31 & 1,56 & 0,001 & nd & 0,011 & nd \\
PA3786 & La Pastora & 10201 & tr & nd & 99,01 & 0,97 & 0,003 & nd & 0,001 & nd \\
PA3788 & La Pastora & 10203 & 0,05 & nd & 98,68 & 1,25 & 0,002 & tr & 0,008 & nd \\
PA13712 & La Pijotilla & 219 & 0,07 & nd & 97,8 & 1,92 & 0,031 & nd & nd & 0,14 \\
PA13713 & La Pijotilla & 210 & 0,18 & nd & 97,9 & 1,69 & 0,02 & nd & nd & 0,15 \\
\hline
\end{tabular}

Tab. 1. Análisis FRX de las puntas de jabalina estudiadas en este artículo. Valores expresados en \% en peso (nd= no detectado; $\operatorname{tr}=$ trazas). 
elementos minoritarios es siempre más elevado que en los mayoritarios y puede aumentar con la proximidad a los límites de detección del elemento. Este margen de error porcentual (hasta el $100 \%$ del valor obtenido) tiene en realidad una expresión cuantitativa limitada, es decir, para un valor del $0,05 \%$, un error del $100 \%$ nunca podría superar un $0,1 \%$. Los resultados de un análisis repetido en distintas partes de un objeto pueden variar dentro de ese margen de error, aumentando las diferencias cuanto más reducida sea el área cubierta en la toma analítica concreta. Cuando los análisis son en área grande, como los realizados con los equipos de FRX del Proyecto de Arqueometalurgia (Rovira et al. 1997), estos efectos quedan parcialmente minimizados.

Incluso con ese amplio margen de error es posible definir un modelo de impurezas a nivel general si se trabaja con series analizadas en las mismas condiciones. La presencia en el metal de otros elementos con porcentajes que superan un orden de magnitud numérico señala una diferencia comparativa, ya sea de una pieza en relación a un conjunto o entre conjuntos. Estadísticamente ya no resulta concluyente valorar diferencias menores en el contenido de las impurezas que se detecten. Un riesgo añadido es intentar aplicar ese modelo de impurezas con datos analíticos no homogéneos.

Para las puntas de jabalina de La Pastora se señalaba (Montero y Teneishvili 1996: 79) que, al no haber contradicción entre los datos composicionales de las jabalinas y los de los objetos de metal geográfica y cronológicamente próximos, no había el menor indicio para sustentar una posible procedencia foránea.

Además minerales arsenicados con proporciones bajas de elementos, como plata o antimonio, capaces de producir composiciones similares a las puntas de jabalina y a los objetos de metal de los yacimientos del suroeste peninsular se han identificado tanto en los propios poblados calcolíticos (un buen ejemplo es Amarguillo II) como en minas de las provincias de Huelva, Sevilla, Córdoba o Badajoz (Hunt 2003).

\section{EL ORIGEN DEL METAL: ANÁLISIS DE LAS PUNTAS DE JABALINA TIPO LA PASTORA MEDIANTE ISÓTOPOS DE PLOMO}

En primer lugar se tratará de confirmar la compatibilidad isotópica del metal de las puntas de jabalina de La Pastora y La Pijotilla con las mineralizaciones y producciones locales (surpeninsulares). Para ello los nuevos datos aquí presentados se compararan con los disponibles en publicaciones de minerales y yacimientos arqueológicos de la Península Ibérica. Posteriormente se valorará también la posibilidad de una procedencia de las puntas de jabalina de las mineralizaciones del Mediterráneo oriental.

Se han analizado 5 muestras tomadas en las puntas de La Pastora N. ${ }^{\circ}$ Inv. 10197 (PA3783), 10201 (PA3786) y 10203 (PA3788), depositadas en el MAN, y en las puntas de La Pijotilla N. ${ }^{\circ}$ Inv. 219 (PA13712) y 201 (PA13713), ahora en el Museo Arqueológico Provincial de Badajoz (Figs. 2 a 4; Tab. 2).

Los análisis, efectuados en el Servicio de Geocronología y Geoquímica (SGIker) de la Universidad del País Vasco, utilizaron un espectrómetro de masas de alta resolución y multicolección con fuente de plasma acoplado inductivamente $(M C$ ICP-MS Neptune). Esta técnica permite analizar muestras más pequeñas y corregir satisfactoriamente el fraccionamiento instrumental mediante la adición de $\mathrm{Tl}$, proporcionando precisión, exactitud y reproducibilidad comparables a los méto-

\begin{tabular}{|l|l|c|c|c|c|c|c|}
\hline Yacimiento & Análisis & 208Pb/206Pb & 207Pb/206Pb & 206Pb/204Pb & 207Pb/204Pb & 208Pb/204Pb & As \% \\
\hline La Pastora & PA3783 & 2,1055 & 0,8618 & 18,111 & 15,609 & 38,134 & 1,56 \\
La Pastora & PA3786 & 2,0952 & 0,8551 & 18,288 & 15,638 & 38,316 & 0,97 \\
La Pastora & PA3788 & 2,0982 & 0,8542 & 18,325 & 15,654 & 38,451 & 1,25 \\
La Pijotilla & PA13712 & 2,0999 & 0,8591 & 18,199 & 15,635 & 38,218 & 1,92 \\
La Pijotilla & PA13713 & 2,0773 & 0,8435 & 18,565 & 15,659 & 38,564 & 1,69 \\
\hline
\end{tabular}

Tab. 2. Resultados de los análisis de isótopos de plomo de las puntas de jabalina por $M C-I C P-M S$ y contenido en arsénico según el análisis por FRX realizado dentro del Proyecto de Arqueometalurgia de la Península Ibérica (Rovira Llorens et al. 1997: 346-347). 
dos complejos de doble o triple spike con espectrómetros de fuente de ionización térmica (TIMS).

Para investigar las relaciones con las producciones locales contemporáneas se dispone de datos isotópicos de plomo de minerales del sur de la Península Ibérica (Arribas y Tosdal 1994; StosGale et al. 1995; Marcoux 1998; Hunt Ortiz 2003; Tornos y Chiarada 2004; Santos Zalduegui et al. 2004; Klein et al. 2009) que incluyen la Zona Sudportuguesa y Ossa-Morena (Fig. 5) y en materiales arqueológicos de los propios yacimientos de Valencina (Roquetito I y El Algarrobillo) (Hunt Ortiz 2003: 151) y La Pijotilla (Hunt Ortiz 2003: 169) y de sus entornos geográficos como, respectivamente, Amarguillo (Los Mola- res, Sevilla) (Hunt Ortiz 2003: 161) o San Blas (Cheles, Badajoz) (Hunt Ortiz et al. 2009).

Mención aparte merece un trabajo reciente que informa de la realización de análisis de isótopos de plomo a otras dos puntas de jabalina de La Pastora, depositadas en el Museo Arqueológico de Sevilla (RE328-7 y RE328-4). Los resultados analíticos isotópicos darían pie a considerarlas fabricadas con minerales de diversos metalotectos surpeninsulares (Nocete et al. 2010: 3841) pero, desgraciadamente, no se publican. La misma falta de publicación de los datos nos impide incorporar en este estudio comparativo otros materiales metalúrgicos de Valencina y de metalotectos del entorno del Valle del Guadalquivir (Nocete et al. 2008; Nocete et al. 2011).

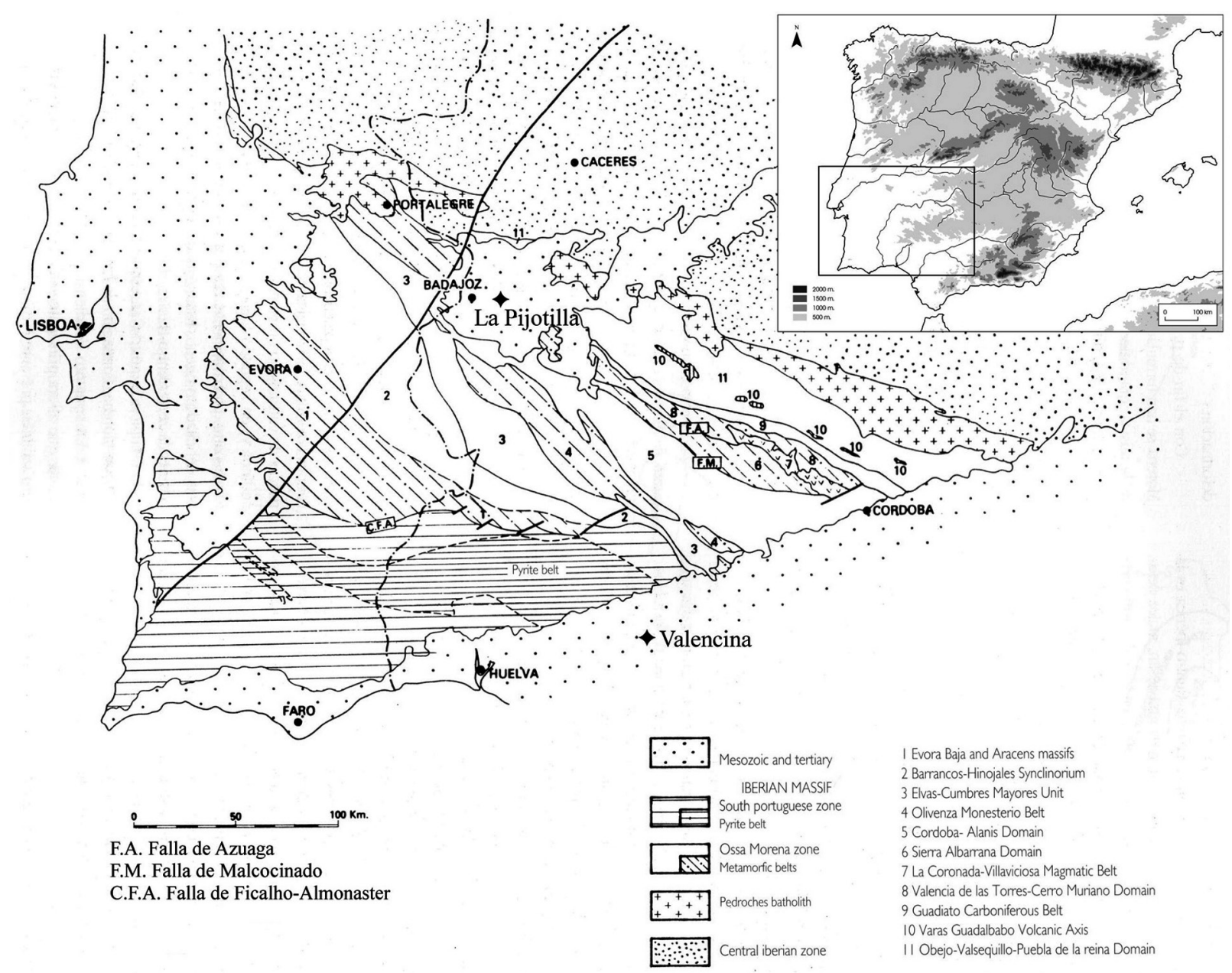

Fig. 5. Zonas geológicas del suroeste de la Península Ibérica con la localización de los yacimientos de La Pijotilla (Badajoz) y Valencina de la Concepción (Sevilla) (según Junta de Extremadura 1993: 42 modificado). 


\subsection{Comparación con las mineralizaciones locales}

La primera cuestión planteada es confirmar la compatibilidad isotópica del metal de las puntas de jabalina de La Pastora y La Pijotilla con las mineralizaciones y producciones locales contemporáneas. Las signaturas isotópicas de las mineralizaciones de Sierra Morena (Zona de OssaMorena y Los Pedroches) presentan una gran heterogeneidad, lo que genera un campo isotópico general amplio. Esta amplitud viene definida por la inclusión en este área de numerosos yacimientos minerales que se agrupan en distintos distritos (Fig. 5). Un mayor número de muestras de cada uno de ellos quizás permitiría delimitar de una forma más exacta las posibles áreas fuente de las materias primas utilizadas en la fabricación de artefactos metálicos. La situación varía para la Zona Sudportuguesa (que incluye las mineralizaciones de la Faja Pirítica -FP-), cuyo campo isotópico general queda bien definido.
Para visualizar mejor esta situación y confrontar las ratios isotópicas de los objetos arqueológicos, se ha representado en las gráficas cada una de las muestras minerales de Ossa-Morena y Pedroches y se ha trazado el campo isotópico de la Zona Sudportuguesa, localizando las muestras de Aznalcóllar, el área mineralizada más próxima a Valencina de la Concepción (Fig. 6).

Los resultados isotópicos obtenidos en las 3 puntas de jabalina de La Pastora y las 2 de La Pijotilla, comparados directamente con los datos geológicos, muestran que la composición de la pieza N. ${ }^{\circ}$ Inv. 219 de La Pijotilla es compatible con mineralizaciones de la Faja Pirítica (Fig. 6), en cuyo límite también se sitúa la muestra N. ${ }^{\circ}$ Inv. 10197 (PA3783) de La Pastora. La composición isotópica de las otras 3 muestras analizadas no es consistente con la Zona Sudportuguesa, aunque sí con mineralizaciones de Ossa-Morena/Los Pedroches, como se ha indicado, con campo isotópico muy amplio. Una zona a tener en cuenta como posible procedencia son

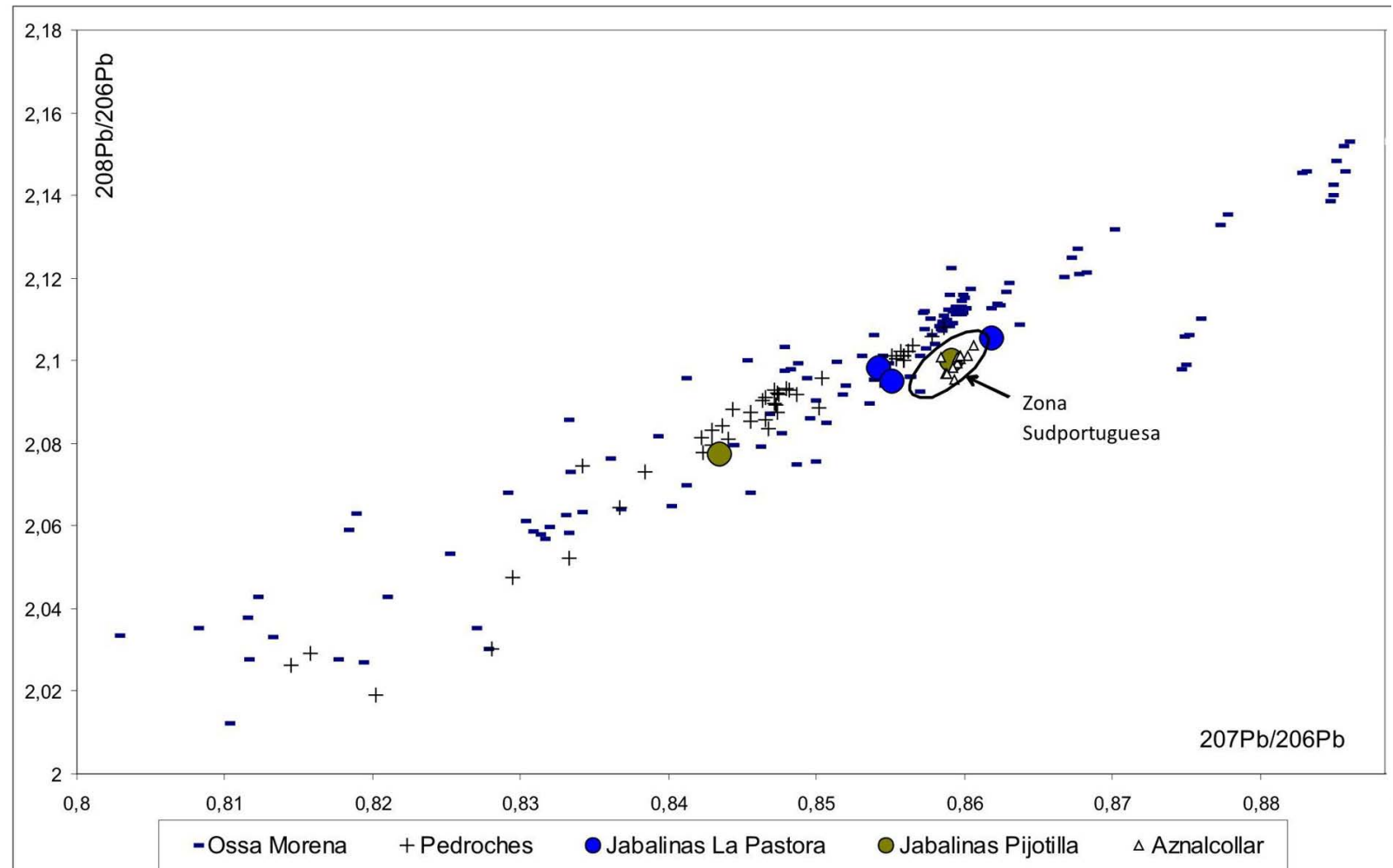

Fig. 6. Gráfico isotópico de las mineralizaciones del suroeste de la Península Ibérica confrontadas con las puntas de jabalina de La Pastora (Valencina de la Concepción) y La Pijotilla (Badajoz). 
los yacimientos peribatolíticos de Los Pedroches, ya que las otras dos jabalinas de La Pastora presentan bastante similitud con algunas de estas minas, especialmente con la muestra Norte Torrecampo. En la zona del batolito de Los Pedroches predominan los minerales de galena y esfalerita, pero también se ha identificado calcopirita y exis- ten registros de minas de cobre desde el siglo XVII (González 1832: 424-425).

Clarifica notablemente la situación (Fig. 7) ampliar la comparación entre materiales arqueometalúrgicos de La Pijotilla, yacimiento de procedencia de las jabalinas, con otros como Roquetito I y El Algarrobillo para Valencina,
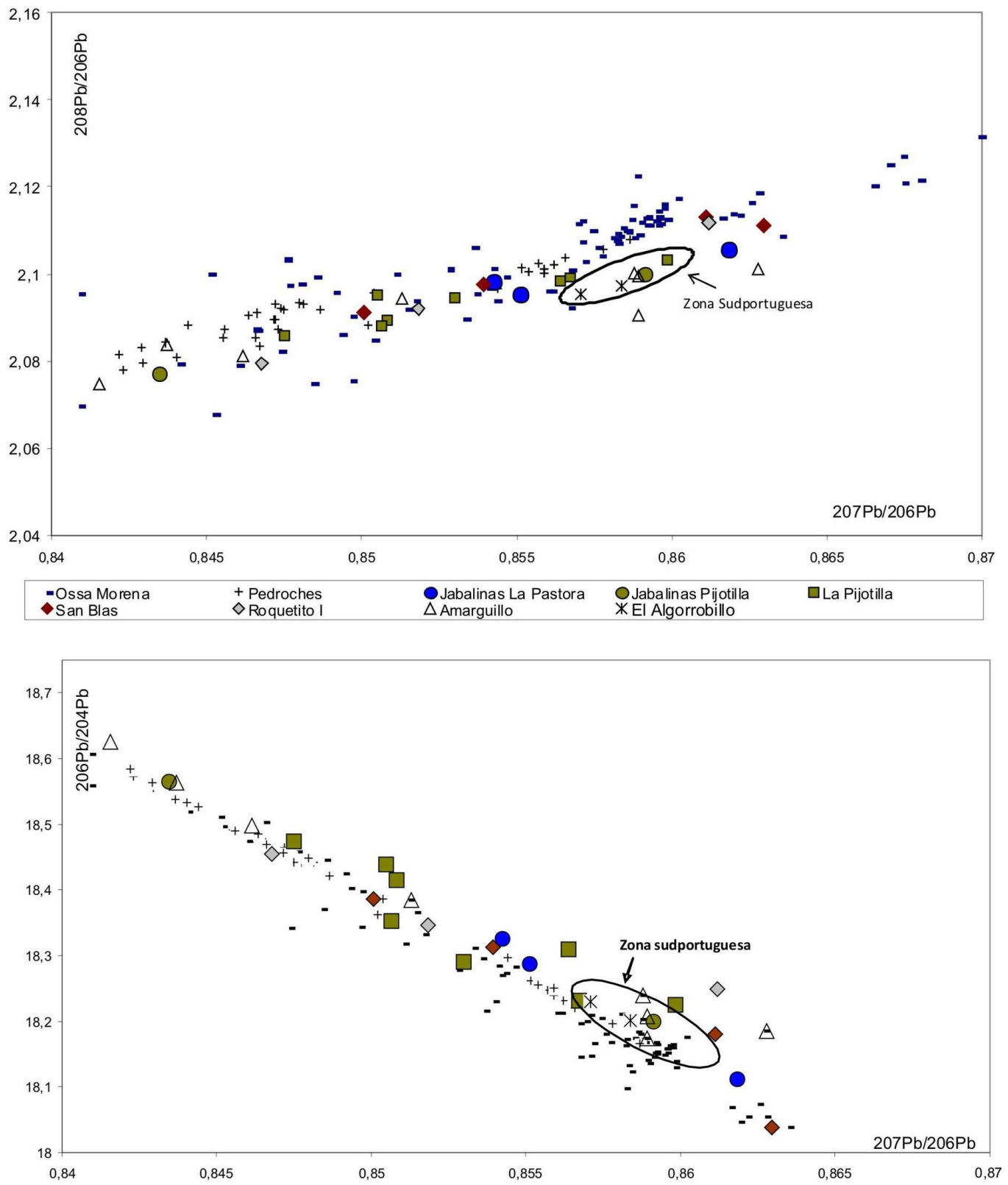

Fig. 7. Gráficos isotópicos de las mineralizaciones del suroeste de la Península Ibérica, las puntas de jabalina de La Pastora (Valencina de la Concepción) y La Pijotilla (Badajoz) y el registro arqueometalúrgico de los yacimientos de Valencina (Roquetito I/El Algarrobillo), Amarguillo, La Pijotilla y San Blas (identificaciones en Tab. 3). 
a los materiales de San Blas y Amarguillo (Tab. 3).

Se confirma la consistencia de los resultados isotópicos con el aprovechamiento de los recursos de la Faja Pirítica en ese registro de Amarguillo y de El Algarrobillo en Valencina, así como el uso de minerales de Ossa Morena/Los Pedroches en San Blas y también en Roquetito, en Valencina. En esta perspectiva hay que destacar que están representados algunos minerales (especialmente de Amarguillo) que no se relacionan directamente con los datos geológicos conocidos (Hunt Ortiz 2003: 241). Esta situación pone en evidencia la actual limitación en la caracterización isotópica de zonas geológicas del suroeste peninsular y de su complejidad para poder precisar más detalladamente el origen del metal. Los minerales y las piezas arqueológicas pueden cubrir vacíos de información geológica.

El punzón n. ${ }^{\circ} 407$ de San Blas y la jabalina n. ${ }^{\circ} 10203$ (PA3788) de La Pastora, cuya signatura isotópica es muy similar (Fig. 8), independientemente de la procedencia concreta que pueda determinarse, muy probablemente tengan el mismo origen.

Se puede concluir que, como se había indicado a partir de los datos proporcionados por el análisis elemental (Montero y Teneishvili 1996), la información disponible de los análisis de isótopos de plomo apunta a que el metal empleado en

\begin{tabular}{|c|c|c|c|c|c|c|c|c|}
\hline Yacimiento & Objeto & $\begin{array}{l}\text { Refe- } \\
\text { rencia }\end{array}$ & $\begin{array}{l}208 \mathrm{~Pb} / \\
206 \mathrm{~Pb}\end{array}$ & $\begin{array}{l}207 \mathrm{~Pb} / \\
206 \mathrm{~Pb}\end{array}$ & $\begin{array}{l}206 \mathrm{~Pb} / \\
204 \mathrm{~Pb}\end{array}$ & $\begin{array}{l}207 \mathrm{~Pb} / \\
204 \mathrm{~Pb}\end{array}$ & $\begin{array}{l}208 \mathrm{~Pb} / \\
204 \mathrm{~Pb}\end{array}$ & Referencia \\
\hline Amarguillo & Espátula & $\mathrm{Agc}$ & 2,0748 & 0,8416 & 18,626 & 15,675 & 38,645 & Hunt 2003 \\
\hline Amarguillo & Hacha & Agb & 2,0839 & 0,8437 & 18,564 & 15,662 & 38,686 & Hunt 2003 \\
\hline Amarguillo & Sierra & Aga & 2,0995 & 0,8589 & 18,207 & 15,638 & 38,226 & Hunt 2003 \\
\hline Amarguillo & Metal informe & AG4 & 2,0811 & 0,8462 & 18,498 & 15,652 & 38,496 & Hunt 2003 \\
\hline Amarguillo & Mineral Cu & Agj & 2,0945 & 0,8513 & 18,384 & 15,650 & 38,505 & Hunt 2003 \\
\hline Amarguillo & Mineral $\mathrm{Cu}$ & Agn & 2,1012 & 0,8628 & 18,185 & 15,690 & 38,211 & Hunt 2003 \\
\hline Amarguillo & Mineral $\mathrm{Cu}$ & $\mathrm{Agl}$ & 2,1002 & 0,8588 & 18,24 & 15,664 & 38,308 & Hunt 2003 \\
\hline Amarguillo & Mineral $\mathrm{Cu}$ & Agh & 2,0906 & 0,8589 & 18,174 & 15,610 & 37,995 & Hunt 2003 \\
\hline El Algarrobillo & Cincel & RQ4 & 2,0973 & 0,8584 & 18,201 & 15,623 & 38,174 & Hunt 2003 \\
\hline El Algarrobillo & Puñal? & RQ5 & 2,0954 & 0,8571 & 18,23 & 15,625 & 38,200 & Hunt 2003 \\
\hline La Pijotilla & Varilla & P28 & 2,1035 & 0,8598 & 18,225 & 15,670 & 38,336 & Hunt 2003 \\
\hline La Pijotilla & Puñal Hoja? & P10 & 2,0896 & 0,8508 & 18,415 & 15,668 & 38,481 & Hunt 2003 \\
\hline La Pijotilla & Metal informe & P25 & 2,0882 & 0,8506 & 18,352 & 15,611 & 38,323 & Hunt 2003 \\
\hline La Pijotilla & Masa metálica & P15 & 2,0860 & 0,8475 & 18,474 & 15,657 & 38,537 & Hunt 2003 \\
\hline La Pijotilla & Metal informe & P29 & 2,0994 & 0,8567 & 18,232 & 15,620 & 38,276 & Hunt 2003 \\
\hline La Pijotilla & Metal informe & $\mathrm{P} 21$ & 2,0305 & 0,8263 & 19,008 & 15,707 & 38,595 & Hunt 2003 \\
\hline La Pijotilla & Lámina metal & P26 & 2,0985 & 0,8564 & 18,31 & 15,680 & 38,424 & Hunt 2003 \\
\hline La Pijotilla & Sierra & P20 & 2,0954 & 0,8505 & 18,439 & 15,682 & 38,638 & Hunt 2003 \\
\hline La Pijotilla & Metal informe & P19 & 2,0947 & 0,8530 & 18,29 & 15,601 & 38,312 & Hunt 2003 \\
\hline Roquetito I & Hacha plana & RQ2 & 2,1118 & 0,8612 & 18,249 & 15,716 & 38,537 & Hunt 2003 \\
\hline Roquetito I & Hacha plana & RQ1 & 2,0794 & 0,8468 & 18,455 & 15,627 & 38,376 & Hunt 2003 \\
\hline Roquetito I & Puñal & RQ3 & 2,0921 & 0,8518 & 18,346 & 15,628 & 38,382 & Hunt 2003 \\
\hline San Blas & Escoria & 411 & 2,0912 & 0,8501 & 18,386 & 15,630 & 38,449 & Hunt et al. 2009 \\
\hline San Blas & Mineral & 256 & 2,1112 & 0,8629 & 18,039 & 15,567 & 38,083 & Hunt et al. 2009 \\
\hline San Blas & Escoria & 419 & 2,0298 & 0,8239 & 18,939 & 15,604 & 38,442 & Hunt et al. 2009 \\
\hline San Blas & Hacha & $520-1$ & 2,1129 & 0,8611 & 18,181 & 15,656 & 38,415 & Hunt et al. 2009 \\
\hline San Blas & Punzón & 407 & 2,0977 & 0,8539 & 18,312 & 15,637 & 38,413 & Hunt et al. 2009 \\
\hline San Blas & Mineral & 64 & 1,9593 & 0,7681 & 20,465 & 15,720 & 40,097 & Hunt et al. 2009 \\
\hline
\end{tabular}

Tab. 3. Análisis de isótopos de plomo de los yacimientos del suroeste de la Península Ibérica utilizados en la figura 7 de este artículo: Amarguillo (Los Molares, Sevilla), El Algarrobillo y Roquetito I (Valencina de la Concepción, Sevilla), La Pijotilla (Badajoz), San Blas (Cheles, Badajoz). 
las puntas de jabalina es compatible con las producciones locales (regionales) y con las mineralizaciones del suroeste de la Península Ibérica. Nocete y sus colaboradores (2010) son de la misma opinión en su valoración de las dos puntas de jabalina que estudian y comparan con los datos inéditos de que disponen de materiales de Valencina de la Concepción y otros yacimientos del suroeste.

\subsection{Comparación con las mineralizaciones del Próximo Oriente}

Una vez constatada la consistencia de los datos isotópicos de las puntas de jabalinas con mineralizaciones locales quedaría por tratar una posible procedencia del Mediterráneo oriental. Se han recopilado datos relativos a las mineralizaciones de Turquía, Grecia, Chipre, Egipto, Palestina, Siria, Omán e Irán y a los elementos metálicos arqueológicos analizados, así como las interpretaciones de los investigadores que los estudiaron. Destacamos el trabajo sobre Hassek Höyük (Schmitt-Strecker et al. 1992) que incorpora datos de 2 puntas de jabalina de la denominada Tumba 12, aunque de tipología algo distinta y de cronología más antigua que las de la Península Ibérica, y los artículos de síntesis encabezados por F. Begemann (Begemann y Schmitt-Strecker 2009; Begemann et al. 2010) sobre la procedencia del metal durante el IV y III milenio a.C.

La signatura isotópica de las jabalinas peninsulares analizadas ocuparía un área cercana a las posiciones isotópicas de las áreas mineralizadas de Feinan y Timna y Omán (Fig. 8), próximas geográficamente al área de distribución de las jabalinas tipo Tell Duweir de Montero Ruiz y Teneishvili (1996) o variante $\mathrm{C}$ en el estudio de Mederos Martín (2000), en el sur de Israel-Palestina. En Fainan tanto los minerales de la formación DLS, la más importante como materia prima en todas las épocas (Hauptmann 2007: 213), como de la formación MBS pueden ser descartados sobre la base de los isótopos (en general ratio $208 \mathrm{~Pb} / 206 \mathrm{~Pb}>2,11$ para la formación DLS). Sin embargo, algunas de las muestras minerales de Timna (wadi Arabah) presentan ratios isotópicos similares a las de las jabalinas de La Pastora. Las puntas de jabalina N. ${ }^{\circ}$ Inv. 10203 (PA7388) de La Pastora y N..$^{\circ}$ Inv. 201 (PA13713) de La Pijotilla, no son consistentes con las minas del wadi Arabah, pero sí las otras tres piezas, aunque siempre en posiciones periféricas (Fig. 8).

La duda que los análisis de isótopos de plomo pueden plantear sobre un origen de las jabalinas en el Mediterráneo oriental queda resuelta valorando la composición de los objetos. Los minerales de Timna y de Feinan apenas contienen arsénico (media de 0,009\% en Timna y $0,0016 \%$ en Feinan, según Hauptman 2007: 79, tabs. 4.2 y 201) y su uso no podría resultar en la producción de cobres arsenicados como los que se detectan en las puntas de jabalina de la Península Ibérica.

Finalmente Omán es la otra zona en el Mediterráneo oriental con signaturas isotópicas similares (Begemann et al. 2010). Además de la posición externa de las jabalinas de la Península Ibérica a la distribución de los minerales (Fig. 8) y periférica en otras comparaciones, hay que valorar la incompatibilidad en la composición. Mientras las impurezas elevadas de níquel son norma tanto en los minerales como en los objetos arqueológicos de Omán, faltan tanto en las jabalinas como en otras piezas metálicas del Calcolítico y de la Edad del Bronce del suroeste peninsular.

Tampoco se ha determinado relación isotópica entre las jabalinas de la Península Ibérica y los objetos de metal del Próximo Oriente. Ni en Hassek Höyük (Schmitt-Strecker et al. 1992), ni en los materiales de cobre mesopotámicos de época Uruk o Acadia (Begemann et al. 2009) se regis-

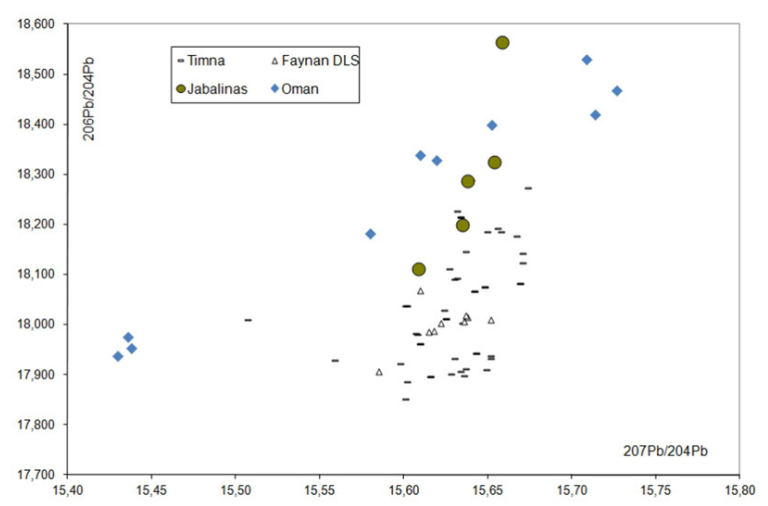

Fig. 8. Gráfico isotópico de las mineralizaciones del Mediterráneo oriental y de las puntas de jabalina de La Pastora (Valencina de la Concepción, Sevilla) y La Pijotilla (Badajoz). 


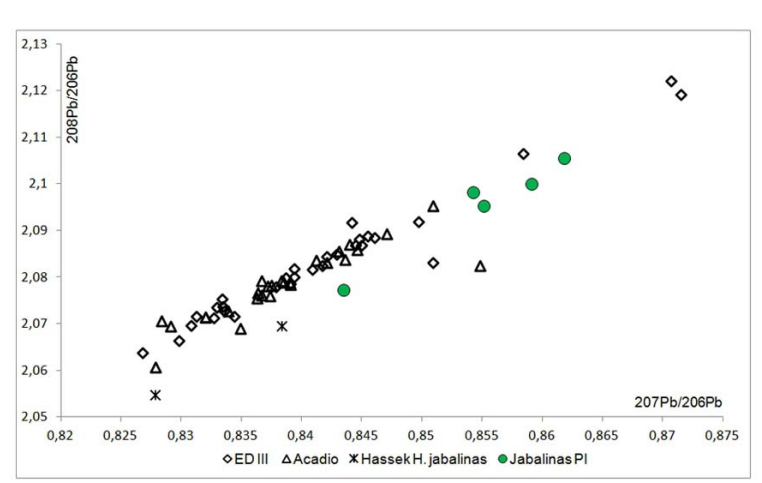

Fig. 9. Gráfico isotópico de los elementos metálicos del Mediterráneo oriental (incluyendo las jabalinas de Hassek Höyük, Turquía) y de las puntas de jabalina de (Valencina de la Concepción, Sevilla) y La Pijotilla (Badajoz).

tran relaciones isotópicas compatibles (Fig. 9). Estos materiales orientales se vinculan directamente a mineralizaciones de Anatolia e Irán, además de a las de Omán.

\section{CONCLUSIONES}

El estudio comparado de los resultados de isótopos de plomo y análisis elemental no permite considerar las puntas de jabalina de La Pastora como piezas importadas desde el Mediterráneo oriental. Las mineralizaciones orientales que isotópicamente podrían ser compatibles presentan unas características de impurezas (arsénico o níquel) incompatibles con la composición de las piezas de la Península Ibérica. A su vez, las mineralizaciones que por composición podrían producir metales con las impurezas detectadas en las jabalinas son incompatibles isotópicamente. Por el contrario, sí hay compatibilidad tanto en la composición como en las signaturas isotópicas de las jabalinas tipo La Pastora analizadas con las mineralizaciones del suroeste peninsular (Faja Pirítica, Los Pedroches y zona de Ossa-Morena) para sustentar una producción local de estas puntas de proyectil.

La variabilidad isotópica detectada en este limitado muestreo visibiliza una procedencia diversa en el abastecimiento de recursos minerales (como mínimo 2 zonas geológicas distintas), coincidente con el panorama ya descrito en el suroeste de la Península Ibérica (Hunt 2003) para el metal del Calcolítico y Bronce Antiguo y que se va conociendo también en otras zonas peninsulares. Esa diversidad de recursos minerales locales aprovechados se señala también en los análisis de isótopos sobre materiales del sureste (Montero-Ruiz y Murillo-Barroso 2010), de la Comunidad de Madrid (8) y de Cataluña meridional(9), lo que permite valorar la situación del aprovechamiento de recursos minerales metálicos en la Prehistoria Reciente con una perspectiva más global.

A su vez, estos mismos datos refuerzan la idea de que las piezas del conjunto de La Pastora se manufacturaron de manera independiente, tal y como las propias diferencias morfológicas entre ellas ya apuntaban (Montero y Teneishvili 1996). Ahora también se conoce que existen variantes formales a escala regional, con la punta de jabalina de Outeiro de São Bernardo como elemento más expresivo de esa variabilidad por su sección cuadrangular y reducido tamaño (Cardoso et al. 2002: 101). Esa punta y las de La Pijotilla muestran el grado de interrelación cultural existente en el cuadrante suroccidental que otros elementos metálicos contemporáneos como las hojas de puñal laminares (de espesor fino) empiezan a delimitar. La inspiración formal de este tipo de objetos es una cuestión que inevitablemente permanecerá abierta.

La localización de puntas de jabalina tipo La Pastora en La Pijotilla (Badajoz) y Outeiro de São Bernardo (Moura) ha triplicado la distribución de estas producciones metálicas por el suroeste de la Península Ibérica sin incrementar en la misma proporción los elementos para su datación. En el sitio epónimo, las últimas interpretaciones valoran la extraordinaria longitud del corredor del tholos y su orientación, poco frecuente, para proponer su construcción hacia 2300-2200 a.C. en función de la posición de Sirio en el firmamento (Belmonte y Pimenta 2001: S60). Ese momento valdría también para el cierre del monumento mediante un ritual que incluiría el depó-

(8) Estudiados por el proyecto El patrimonio arqueológico y documental de la Comunidad Autónoma de Madrid: Sistematización, gestión, puesta en valor y difusión desde el ámbito local al marco europeo (PADCAM) (S2007/HUM-543) financiado por la Comunidad de Madrid.

(9) Investigaciones en curso dentro del proyecto de I+D+I del Plan Nacional Relación entre materias primas locales y producción metalúrgica: Cataluña meridional como modelo de contraste (HAR2010-21105-C02-02). 
sito de puntas de jabalina (García Sanjuán 2009: 234), aunque los citados autores ya previenen sobre la realimentación entre esa cronología y la opción por Sirio.

Las excavaciones efectuadas desde la década de 1990 en el entorno de Valencina de la Concepción más próximo al tholos han localizado uno o varios poblados prehistóricos. De uno o varios de ellos es presumible que procedieran los constructores del monumento. Las numerosas estructuras, bien fechadas por dataciones absolutas y materiales asociados, documentan una ocupación de duración milenaria sin elementos con una conexión tan clara con La Pastora como para facilitar su datación precisa y/o la de las puntas de proyectil.

Algo similar ocurre con la Pijotilla. Este asentamiento calcolítico está bien delimitado (80 ha) pero cuenta con estructuras de arquitectura y funcionalidad compleja y amplia cronología. Su registro, que incluye cerámicas campaniformes de estilos internacional y regional o inciso, es demasiado rico y variado para la contextualización concreta de las puntas de jabalina halladas en superficie.

Por su parte, el ejemplar de Outeiro de São Bernardo formaba parte de un conjunto de piezas metálicas recuperado en el sondeo abierto en la zona superior del poblado, en una capa de $15 \mathrm{~cm}$ de potencia. Ese contexto estratigráfico define las primeras asociaciones tipológicas directas de una punta de jabalina, entre la que se destaca la existente con una sierra con enmangue de lengüeta que incorpora una perforación para un posible remache. Aunque es un tema aún no tratado en profundidad por la investigación, este rasgo apuntaría hacia un momento bastante avanzado del Calcolítico, ya en su transición con la Edad del Bronce. Por desgracia, la caracterización del contexto es incompleta, faltando además dataciones absolutas. Cardoso et al. (2002: 77, 101) sitúan el conjunto a fines del Calcolítico/inicios de la Edad del Bronce, en los últimos siglos del III milenio a.C., basándose en la tipología y composición de los objetos, en la presencia de cerámicas campaniformes incisas en el poblado y en que ese estilo cerámico se asocia con algunos de los tipos metálicos de Outeiro de São Bernardo en otros yacimientos. Destaca la similitud tipológica de las piezas metálicas halladas en Outeiro de São Bernardo y La Pijotilla, en especial las sierras, los cuchillos dentados y los puñales con eje cen- tral reforzado, cuya comparación es ya advertida en el estudio de Cardoso y colaboradores (2002: 97-98). Esta circunstancia redundaría en la idea ya apuntada sobre las estrechas interrelaciones que se produjeron en el suroeste y, en ese caso, en el entorno del Guadiana.

Aceptada la posibilidad del uso coetáneo, más o menos prolongado, de las cerámicas campaniformes de estilo regional y de las puntas de jabalina tipo La Pastora quedaría, por último, intentar concretar la cronología. La discusión de los contextos campaniformes del suroeste de la Península Ibérica con fechas absolutas (Odriozola et al. 2008: 220-222) muestra las dificultades inherentes a la seriación de los estilos campaniforme y a la datación de recipientes individuales, incluso a escala regional. Algunas derivan del carácter de "reliquia” familiar que se asigna a estos vasos, transmitidos de generación en generación, otras de las divergencias entre datos estratigráficos, secuencias aceptadas y/o dataciones. Considerando las 21 dataciones radiocarbónicas de los contextos con campaniforme correspondientes a los 7 sitios que se manejan (Odriozola et al. 2008: 221, Fig. 6), el límite inferior y superior de los rangos de la más antigua (Leceia FM) y la más moderna (Palacio Quemado 2, Zambujal 3B/C) definen un período de utilización de estas cerámicas decoradas que cubre todo el III milenio, incluyendo las centurias de transición entre el III y el II milenio a.C.

Este estudio, con la incorporación de nuevos datos y la revisión de los conocidos, debería retraer la consideración inmediata de las puntas de jabalina tipo La Pastora como prueba clave de las relaciones externas de las primeras sociedades metalúrgicas de la Península Ibérica. Como se ha expuesto, este tipo metálico adolece todavía de imprecisiones sobre la identidad de las mismas y sobre su período de uso. En cambio, su producción local parece bien constatada por datos morfométricos y de composición de las puntas de proyectil y de los minerales fuente. Los datos disponibles hasta la fecha sobre la distribución de las piezas, sus características y las de las mineralizaciones indican que fueron producidas en el suroeste peninsular.

\section{AGRADECIMIENTOS}

El Museo Arqueológico Nacional (Madrid) (Patronato y dirección, Departamento de Prehis- 
toria: Carmen Cacho, conservadora-jefe y Eduardo Galán, conservador) apoyó la investigación arqueometalúrgica y archivística de las puntas de jabalina allí depositadas, en un momento de especial complejidad para el museo por la reforma en marcha. El proyecto 2010RU0086_2012 (Provincias metalúrgicas Euroasiática y Europea del II milenio a.n.e.: investigación de sus interacciones a partir de métodos científico-naturales, Russian Foundation for Basic Research - CSIC, investigadora responsable M.I.M.N.) financió los análisis de isótopos de plomo de las puntas de $\mathrm{La}$ Pastora del museo madrileño y el proyecto de la Junta de Andalucía MAT2005-00790 (Tecnología de Materiales de Recursos Abióticos en la Prehistoria Reciente, III-II milenios cal ANE, en el Suroeste de España: Tierra de Barros y Sierra Morena Occidental (investigador responsable V.H.P.) los realizados a las puntas de jabalina de La Pijotilla. El estudio se encuadra dentro de las actividades de investigación del subproyecto HAR2010-21105-C02-02 del Plan Nacional de I+D+I (investigador responsable I.M.R.).

\section{BIBLIOGRAFÍA}

Almagro Basch, M. 1962: "El ajuar del 'Dolmen de la Pastora' de Valentina del Alcor [sic] (Sevilla). Sus paralelos y su cronología". Trabajos de Prehistoria 5: 1-35.

Arribas, A. y Tosdal, R. M. 1994: "Isotopic composition of $\mathrm{Pb}$ and $\mathrm{S}$ in base and precious metal deposits of the Betic Cordillera, Spain: origin and relationship to other European deposits". Economic Geology 89: 1074-1093.

Belén, M. 1991: “Apuntes para una historia de la arqueología andaluza: Francisco M. Tubino (18331888)". Boletín del Museo Arqueológico Nacional IX: 7-15.

Begemann, F.; Hauptmann, A.; Schmitt-Strecker, S. y Weisberger, G. 2010: "Lead isotope and chemical signature of copper from Oman and its occurrence in Mesopotamia and sites on the Arabian Gulf coast". Arabian Archaeology and Epigraphy 21(2): 135-169.

Begemann, F. y Schmitt-Strecker, S. 2009: "Über das frühe kupfer mesopotamiens”. Iranica Antiqua 44: $1-45$.

Belmonte, J. A. y Pimenta, F. 2001: "Matarrubilla and La Pastora, Valencina de la Concepción, Sevilla". En M. Hoskin (ed.): Studies in Iberian Archaeoastronomy: (8) Orientations of megalithic and tholos tombs of Portugal and Southern Spain. Archaeoas- tronomy 26, Supplement of Journal for the History of Astronomy XXXII: S59-S61.

Berdichewsky Scher, B. 1964: Los enterramientos en cuevas artificiales del Bronce I Hispánico. Bibliotheca Praehistorica Hispana VI, CSIC, Universidad de Madrid. Madrid.

Candau y Pizarro, F. 1894: Prehistoria de la provincia de Sevilla. Imprenta de C. Salas. Sevilla.

Cañal, C. 1894: Sevilla Prehistórica. Yacimientos prehistóricos de la provincia de Sevilla. Librería de Fernando Fé. Madrid/Librería de Juan A. Fé. Sevilla.

Cardoso, J. L.; Monge Soares, A. M. y Araújo, M. de F. 2002: "O espólio metálico do Outeiro de S. Bernardo (Moura): uma reapreciaciâo à luz de velhos documentos e de outros achados". O Arqueólogo Português IV, 20: 77-114.

Carriazo, J. de M. 1973: Tartesos y El Carambolo. Investigaciones arqueológicas sobre la Prehistoria de la Baja Andalucía. Ministerio de Educación y Ciencia. Madrid.

Costa Caramé, M. E. 2011: La metalurgia y sus repercusiones económicas, sociales e ideológicas en las Comunidades del III y II Milenio CALANE en el Suroeste de la Península Ibérica. Tesis doctoral Universidad de Sevilla, Fac. Geografía e Historia, Dpto. de Prehistoria y Arqueología. http://fondosdigitales.us.es/ tesis/tesis/1563/la-metalurgia-y-sus-repercusioneseconomicas-sociales-e-ideologicas-en-las-comunidades-del-iii-y-ii-milenio-cal-ane-en-el-suroestede-la-peninsula-iberica/(acceso 14-IX-2011).

Cruz-Auñón, R. y Arteaga Matute, O. 2001: "La Alcazaba. Un espacio social aledaño a la periferia del poblado prehistórico de Valencina de la Concepción (Sevilla). Excavación de urgencia de 1996". Anuario Arqueológico de Andalucía 1996: 701-707.

Escacena Carrasco, J. L. 2008: "Cantos de sirena: la precolonización fenicia de Tartessos". En S. Celestino Pérez, N. Rafel i Fontanals y X. L. Armada Pita (ed.): Contacto cultural entre el Mediterráneo y el Atlántico (siglos XII-VIII ane). La precolonización a debate. CSIC, Escuela Española de Historia y Arqueología en Roma. Madrid: 301-322.

Ferreira, O. da Veiga 1970: "Um esconderijo de fundidor encontrado no Castro de S. Bernardo (Moura)". O Arqueólogo Português serie III, 5: 139-143.

García Sanjúan, L. 2005: "Las piedras de la memoria. La permanencia del megalitismo en el suroeste de la Península Ibérica durante el II y I milenios ANE". Trabajos de Prehistoria 62 (1): 85-109.

García Sanjuán, L. 2009: "Sevilla". En L. García Sanjuán y B. Ruiz González (eds.): Las grandes piedras de la Prehistoria. Sitios y paisajes megalíticos de Andalucía. Junta de Andalucía, Consejería de Cultura. Sevilla: 228-260.

González, T. 1832: Registro y relación general de minas de la corona de Castilla I. Madrid. http://

Trab. Prehist., 69, N. ${ }^{\circ} 2$, julio-diciembre 2012, pp. 357-374, ISSN: 0082-5638

doi: $10.3989 /$ tp.2012.12097 
bibliotecadigital.jcyl.es/i18n/consulta/registro. cmd?id=4521 (consulta 11-IX-2012).

Hauptmann, A. 2007: The Archaeometallurgy of Copper: Evidence from Faynan, Jordan. Springer. Heidelberg, Berlin, New York.

Hunt Ortiz, M. 2003: Prehistoric Mining and Metallurgy in South West Iberian Peninsula. British Archaeological Reports, International Series 1188, Archaeopress. Oxford.

Hunt Ortiz, M. A.; Hurtado Pérez, V.; Montero Ruiz, I.; Rovira Llorens, S. y Santos Zalduegui, J. F. 2009: "Chalcolithic metal production and provenance in the site of San Blas (Cheles, Badajoz, Spain)". En Archaeometallurgy in Europe 2007. Selected Papers of the 2nd. Internacional Conference Archaeometallurgy in Europe (Grado-Aquileia 2007): 81-92 Milán.

Hurtado Pérez, V. 1988: "Informe sobre las campañas de excavaciones arqueológicas en La Pijotilla (1980-85)”. Extremadura Arqueológica I: 35-54.

Hurtado Pérez, V. 1991: "Informe de las excavaciones de urgencia en 'La Pijotilla' (Badajoz), campaña 1990”. Extremadura Arqueológica II: 45-68.

Hurtado Pérez, V. 1995: "Interpretación sobre la dinámica cultural en la Cuenca Media del Guadiana (IV-II milenios a.n.e.)". Extremadura Arqueológica V: 53- 81.

Hurtado Pérez, V. y García Sanjuán, L. 1996: "La necrópolis de Guadajira y la transición a la Edad del Bronce en la Cuenca Media del Guadiana". Spal. Revista de Prehistoria y Arqueología 3: 95-144.

Hurtado Pérez, V. y Hunt Ortiz, M. 1999: "Extremadura". En G. Delibes de Castro e I. Montero Ruiz (ed.): Las Primeras Etapas Metalúrgicas en la Península Ibérica: II. Estudios Regionales. Instituto Universitario Ortega y Gasset, Fundación Ortega y Gasset, Ministerio de Cultura. Madrid: 241-274.

Junghans, S.; Sangmeister, E. y Schröder, M. 1960: Metallanalysen Kuperzeitlicher und Frühbonzezeitlicher Bodenfunde aus Europa. Studien zu den Anfängen der Metallurgie. Gebr. Mann Verlag. Berlín.

Junghans, S.; Sangmeister, E. y Schröder, M. 1968: Kupfer und Bronze in der frühen Metallzeit Europas. Studien zu den Anfängen der Metallurgie 2. Gebr. Mann Verlag. Berlín.

Junta de Extremadura 1993: Libro de la Minería de Extremadura. Junta de Extremadura, Consejería de Industria y Turismo. Badajoz.

Klein, S.; Domergue, C.; Lahaye, Y.; Brey, G. P. y von Kaenel, H. M. 2009: "The lead and copper isotopic composition of copper ores from the Sierra Morena (Spain). Análisis de los isótopos de plomo y de cobre de los minerales de cobre de Sierra Morena (España)". Journal of Iberian Geology 35 (1): $59-68$.
Marcoux, E. 1998: "Lead isotope systematics in the giant massive sulphide deposits in the Iberian Pyrite belt". Mineralium Deposita 33 (1-2): 45-58.

Martín de la Cruz, J. C. 1991: "La Península Ibérica y el Mediterráneo en el segundo milenio a.C.". En Mundo micénico: cinco siglos de la primera civilización europea, 1600-1100 a.C. Ministerio de Cultura. Madrid: 110-123.

Martínez Boloix, J. 1983: "Córdoba y su aportación a la Cultura del Vaso Campaniforme". Actas del I Congreso de Historia de Andalucía (Córdoba 1976) I, Prehistoria y Arqueología: 135-147. Córdoba.

Martínez Boloix, J. 2002: El Dolmen de Casas de Don Pedro en Sierra Palacios (Bélmez, Córdoba). Estudio Analítico y Metalúrgico de su material de cobre y su incorporación a la Serie Campaniforme provincial. Universidad de Córdoba. Córdoba.

Mederos Martín, A. 2000: "Puntas de jabalina de Valencina de la Concepción (Sevilla) y del área palestino-israelita". Madrider Mitteilungen 41: 83-111.

Montero Ruiz, I. y Murillo-Barroso, M. 2010: "La producción metalúrgica en las sociedades argáricas y sus implicaciones sociales: una propuesta de investigación". Menga: revista de prehistoria de Andalucía 1: 37-52.

Montero Ruiz, I. y Teneishvili, T. O. 1996: "Estudio actualizado de las puntas de jabalina del dolmen de la Pastora (Valencina de la Concepción, Sevilla)". Trabajos de Prehistoria 53 (1): 73-90.

Murillo-Barroso, M. y Montero-Ruiz, I. 2012: “Copper Ornaments in the Iberian Chalcolithic: Technology versus Social Demand". Journal of Mediterranean Archaeology 25(1): 53-73.

Nocete Calvo, F. (ed.) 2004: Odiel: proyecto de investigación arqueológica para el análisis del origen de la desigualdad social en el suroeste de la Península Ibérica. Junta de Andalucía, Consejería de Cultura, Dirección General de Bienes Culturales. Sevilla.

Nocete, F.; Queipo, G.; Sáez, R.; Nieto, J. M.; Inácio, N.; Bayona, M. R.; Peramo, A.; Vargas, J. M.; Cruz-Auñón, R.; Gil-Ibarguchi, J. I. y Santos, J. F. 2008: "The smelting quarter of Valencina de la Concepción (Seville, Spain): the specialised copper industry in a political centre of the Guadalquivir Valley during the Third millennium BC (2750-2500 BC)". Journal of Archaeological Science 35 (12): 717-732.

Nocete Calvo, F.; Rodríguez Bayona, M. e Inácio, N. 2010: "Estudio isotópico $(\mathrm{Pb})$ de las "puntas de la Pastora' (Valencina de la Concepción, Sevilla)". Anuario Arqueológico de Andalucía 2006: 38393844.

Nocete, F.; Sáez, R.; Bayona, M. R.; Peramo, A.; Inácio, N. y Abril, D. 2011: "Direct chronometry (14C AMS) of the earliest copper metallurgy in the Guadalquivir Basin (Spain) during the Third 
millennium BC: first regional database". Journal of Archaeological Science 38 (12): 3278-3295.

Odriozola, C. P.; Hurtado Pérez, V.; Dias, M. I. y Prudêncio, M. I. 2008: "Datación por técnicas luminiscentes de la Tumba 3 y el conjunto campaniforme de La Pijotilla (Badajoz, España)". En S. Rovira Llorens, M. García-Heras, M. Gener Moret e I. Montero Ruiz (eds.): Actas. VII Congreso Ibérico de Arqueometría (Madrid 2007) I: 211-225. Madrid. http://digital.csic.es/handle/10261/30629 (consulta 15-VI-2012).

Parreira, R. 1983: "O Cerro dos Castelos de São Brás (Serpa). Relatório preliminar dos trabalhos arqueológicos de 1979 e 1980". O Arqueólogo Português IV, 1: 149-168.

Roberts, B. W. 2009: "Production Networks and Consumer Choice in the Earliest Metal of Western Europe". Journal of World Prehistory 22: 461-481.

Roberts, B. W.; Thornton, Ch. P. y Pigott, V. C. 2009: "Development of metallurgy in Eurasia". Antiquity 83: 1012-1022.

Rodríguez Bayona, M. 2008: La investigación de la actividad metalúrgica durante el III milenio A.N.E. en el suroeste de la Península Ibérica: la arqueometalurgia y la aplicación de análisis metalográficos y composicionales en el estudio de la producción de objetos de metal. British Archaeological Reports, International series 1769, Archaeopress. Oxford.

Rovira Llorens, S.; Montero Ruiz, I. y Consuegra Rodríguez, S. 1997: Las primeras etapas metalúrgicas en la Península Ibérica. I. Análisis de materiales. Instituto Universitario Ortega y Gasset, Fundación Ortega y Gasset, Ministerio de Cultura. Madrid.

Ruiz Moreno, M. T. y Martín Espinosa, A. 1993: “Excavación de urgencia en el Dolmen de La Pastora, Valencina de la Concepción, Sevilla". Anuario Arqueológico de Andalucía 1991, III: 554-558.

Santos Zalduegui, J. F.; García de Madinabeitia, S.; Gil Ibarguchi, J. I. y Palero, F. 2004: “A lead isotope database: the Los Pedroches-Alcudia area (Spain). Implications for archaeometallurgical connections across south-western and south-eastern Iberia". $A r$ chaeometry 46: 625-634.

Schmitt-Strecker, S.; Begemann, F. y Pernicka, E. 1992: "Chemische Zusammensetzung und Bleiisotopenverhaltnisse der Metalfunde vom Hassek Höyük". En M. R. Behm-Blancke (ed.): Hassek Höyük. Naturwissenschaftliche untersuchungen und Lithische Industrie. Istanbuler Forschungen 38, Ernst Wasmuth Verlag. Tübingen: 108-123.

Schubart, H. 1971: "O horizonte de Ferradeira: sepulturas do Eneolítico final noSudoeste da Península Ibérica". Revista de Guimarães LXXI: 189-215.

Schuhmacher, Th. X. 2011: "Long and middle range contacts in the Early Bronze Age of the Western Mediterranean". En S. Hansen y J. Müller (eds.): Sozialarchäologische Perspektiven: Gesellschaftlicher Wandel 5000-1500 v. Chr. zwischen Atlantik und Kaukasus, Internationale Tagung, Kiel 2007. Archäologie in Eurasien 24, Philipp von Zabern. Berlín: 415-428.

Siret, L. 1913: Questions de chronologie et d'ethnographie ibériques I. Paul Geuthner. Paris.

Stos-Gale, Z. A.; Gale, N. H.; Houghton, J. y Speakman, R. 1995: "Lead isotope data from the isotrace laboratory, Oxford: Archaeometry database 1, ores from the western Mediterranean". Archaeometry 37(2): 407-415.

Tornos, F. y Chiarada, M. 2004: "Plumbotectonic evolution of the Ossa Morena Zone, Iberian Peninsula: tracing the influence ofmantle-crust interaction in ore-forming processes". Economic Geology 99: 965-985.

Tubino, F. M. ${ }^{\text {a } 1868 a: ~ " M o n u m e n t o ~ P r e h i s t o ́ r i c o ~ d e ~}$ Castilleja de Guzman". En Estudios prehistóricos. Oficinas de la "Revista de Bellas Artes". Madrid: 49-59.

Tubino, F. M. ${ }^{a}$ 1868b: "Comunicación de Francisco M. Tubino sobre sustrabajos en la Cueva de La Pastora". La Gaceta de Madrid CCVI, 83, 23 de marzo de 1868: 1-3.

Tubino, F. M. 1875: “... sur les monuments mégalithiques de l'Andalousie". En Congrès International d'Anthropologie et d'Archéologie Préhistoriques. Compte Rendu de la 4e Session, Copenhague, 1869. Imprimerie du Thiele. Copenhague: 93-98.

Vargas Jiménez, J. M.; Nocete Calvo, F. y Ortega Gordillo, M. 2010: "Excavaciones arqueológicas en la parcela del nuevo IES de Valencina de la Concepción (Sevilla)". Anuario Arqueológico de Andalucía 2005, III: 3340-3356.

Viana, A.; Formosinho, J. y Ferreira, O. da Veiga 1953: "Algumas notas sobre o BronzeMediterrãnico do Museu Regional de Lagos". Zephyrus IV-7: 97-117. 